\title{
Determenation'The Porosity of CdS Thin Film by SeedFilling Algorithm
}

\author{
Azmi Tawfik Alrawi ${ }^{1}$, Saad Jasim Mohammed $^{2}$ \\ ${ }^{1}$ Department of Physics, University of Anbar, Ramadi, Iraq \\ Dr_azmi_alrawi@yahoo.com \\ ${ }^{2}$ Department of Physics, University of Anbar, Ramadi, Iraq \\ Sa882003@yahoo.com
}

\begin{abstract}
In this paper, we have prepared CdS thin films by chemical spray method on the substrates in $\left(200 C^{\circ}\right)$ and then we annealed the samples of thin film by oven heat in the temperature $\left(250-400 \mathrm{C}^{\circ}\right)$ and we took images of the thin film membranes before and after annealing by a scanning electron microscope (SEM) in magnification (1000X). The acquisition image converted to binary image of multithresholdand then applied image processing where used seed filling algorithm to analysis images and study the porosity on the surfaces of thin films and that the annealing under different temperature works to reduce the ratioand number of pores on the surface of the thin membrane.
\end{abstract}

\section{KEYWORDS}

Porosity ; Thin Film ; Seed Filling ; Annealing ; Image processing ; CdS Material ; Threshold.

\section{INTRODUCTION}

Porosity is defined as the fraction of the bulk sample volume $\mathrm{V}$ that is not occupied by solid matter. If the volume of solids is denoted by Vs, and the pore volume as $\mathrm{Vp}=\mathrm{V}-\mathrm{Vs}$, we can write the porosity as:[1]

$\phi=\frac{V-V s}{V}=\frac{V p}{V}=\frac{\text { Pore Volume }}{\text { Total Bulk Volume }}$

The major effects of the annealing process are to promote recrystallization leading to grain growth, grain boundarypassivation [2] .Thin films porosity is usually determined using gravimetric or quasi-gravimetric methods [3] .The most obvious and straightforward measurements of pore size and pores distribution are with geometric analysis of images of individual pores. This can be done using various types of microscopy on thin sections or other flat surfaces, or tomographs. Dimensions of pore bodies and necks can be measured manually by computer analysis of digitized images.[1,4]

The original image composed of 256 grey levels, is binarized at a chosen threshold level $T$. The pores are in black and the surface of the thin film is in white. The analysis of the binarized image is based on the digitalization of each pore of the thin film surface followed by the measurement of 
the pore area. The pore density (number of pores per unit area) is deduced from the number of labelized pores on a known surface.[4]

The morphological image processing technologies used in the paper involve logic operations and binary images. Thus, gray-level SEM images are firstly transformed to binary images .There are many segmentation methods that deal with various kinds of Images.[5]

In image processing, region filling or seed filling is used for image analysis and in computer graphics, a specific area of image can be painted out by using thistechnique. There are two parts for seed filling algorithm. First part of this algorithm finds starting seed and connected pixels are second part. Seed points can be searched automatically or they can be chosen by the user. A working memory is needed to keep the record of all seed filling algorithms.[6]

\section{PREVIOUS WORKS}

S. Deshpande,2004: The microstructures of thermally sprayed coatings are very complex and incorporate process-dependent defects such as globular pores, interlamellar pores, cracks (in case of ceramics), etc. Porosity is a prevalent feature in the microstructure and affects a wide range of coating properties such as elastic modulus, thermal conductivity and dielectric behavior. Various methods are employed for quantitative measurement of porosity, which forms an important and integral part of microstructural characterization of thermal spray coatings. Studies have been conducted here to establish image analysis (IA) as a reliable method for characterization of porosity in thermally sprayed coatings. The versatility of IA methods for microstructural quantification has been investigated for diverse coatings deposited with distinct spray processes and material feedstock characteristics. The IA methods put forth have been successfully applied to a variety of thermally sprayed coatings; materials of interest in this study being produced from partially stabilized zirconia (PSZ, $\mathrm{ZrO} 2+8 \%$ Y2O3) and alumina ceramics. The results have been complemented with the microstructural information obtained using advanced characterization techniques, such as small-angle neutron scattering (SANS) and computer micro-tomography (CMT) carried out on similar coatings. The trends shown by these different methods for variation in porosity with respect to feedstock characteristics were in agreement. This study confirms the applicability of image analysis as a straightforward, versatile, reliable and inexpensive method for the characterization of porosity.[7]

Weina Sun,2007: A digital image processing program package was developed to calculate the porosity, pore diameter distribution, pore area distribution, and pore shape distribution of membrane surface by treating the SEM photos of membrane surface and cross-section. Different membranes were prepared and investigated in this experiment, including polyacrylonitrile (PAN), polyaryletherketone with cardo (PEK-C), polyarylethersulfone with cardo (PES-C), polysulfone (PSf), polyvinylidene fluoride (PVDF), and poly(phthalazinone ether sulfoneketone) (PPESK) membranes. Compared with the analysis results of IBAS I/II image analytical instrument (made in Germany), the porosity analyzed by our program package was larger, and the dispersion of distribution was wider. The porosity of membrane cross-section was also determined. The pure water flux (J) and rejection (R) of bovine serum albumin (BSA) of membranes were measured, and the results agree with those obtained from our program. In addition, the gelation front movement was measured using ImageJ program and our program package, respectively, and the results were further compared .[8] 
Chun Liu,2011: A series of image processing technologies and geometric measurement methods is introduced to quantifymultiple scale microporosity in images. All the operations are nondestructive so as to ensure the accuracy of the results. With the application of these methods, various basic geometric parameters of the pores can be computed automatically in the computer, such as area, perimeter, direction etc. On the basis of these geometric parameters, probability entropy, probability distribution index and fractal dimension were introduced to describe the distribution of the three major characteristics of pore system, direction, area and form factor, respectively. Computer software developed on the basis of these methods was used to quantify the SEM images of clay samples during shear test. According to the quantification result, total pore area and average pore form factor reduce during the test. The variation of pore area and form factor is related to probability distribution index and fractal dimension, which indicates the variation of microstructures between pores. Error analysis shows that the deviation using the image processing is within 5\%, and the deviations of statistical parameters are smaller in comparison with those of basic geometric parameters. The statistical methods are adapted to thequantification of 2D multiple scale objects. This paper offers a reliable basis for the quantification and characterization of microporosity by image processing.[5]

\section{EXPERIMENTAL}

\subsection{CdS Thin film preparation}

We prepared CdS Thin film from deposition of cadmium chloride $(\mathrm{CdCl} 2)$ concentration of $(1 \mathrm{M})$ and Althaaoria(CS(NH2)2) concentration of $(1 \mathrm{M})$ by chemical spray method on the substrates of glass with dimensions of $(7.5 * 2.5 \mathrm{~cm})$ hotting in $200 \mathrm{C}^{\circ}$. Where we prepared $(\mathrm{CdCl} 2)$ solution which is the source of $(\mathrm{Cd})$ ions from melting $(1.824 \mathrm{gm})$ of $(\mathrm{CdCl} 2)$ material, which is produced by (chemical Ltd Poole England) of purity of $(99.5 \%)$ in $100 \mathrm{ml}$ of distilled waterand those who also prepared $(\mathrm{CS}(\mathrm{NH} 2) 2)$ solution which is the source of (S)ions from melting ( 0.76 $\mathrm{gm})$ of $(\mathrm{CS}(\mathrm{NH} 2) 2)$ material which is produced by (chemical Ltd Poole England) in (100 ml) of distilled water, the weights of these materials were calculated from the following equation:[9]

$$
\text { Molarity }(M)=\frac{\text { Mnles of solute }}{\text { Liters of solution }}
$$

Where:

$$
\text { Moles of solute }=\frac{\text { Weight of solute (grams) }}{\text { Molecular weight of solute (grams / moles) }}
$$

After that we prepared the solutions above take $40 \mathrm{ml}$ of $(\mathrm{CdCl} 2)$ with $40 \mathrm{ml}$ of $(\mathrm{CS}(\mathrm{NH} 2) 2)$ and we blended by Blender magnetic, and after that we sprayed (CdS) solution on the glass substrates $\left(200 \mathrm{C}^{\circ}\right.$ ) and after complete spraying solution and cooled glass substrates is the thin film has been completed.After that we prepared CdS thin film in $200 \mathrm{C}^{\circ}$, we annealed the thin films in thermal oven temperature in $\left(250,300,350\right.$ and $\left.400 \mathrm{C}^{\circ}\right)$ to observe the impact of thermal annealing on the porosity of $\mathrm{CdS}$ thin films.

\subsection{Image Acquisition}

After that we prepared CdS thin films in $\left(200 \mathrm{C}^{\circ}\right)$ and then we had a process of annealing to different temperatures $\left(250,300,350\right.$ and $\left.400 \mathrm{C}^{\circ}\right)$, we take the samples (before and after the annealing process), and enlarge it using a scanning electron 
microscope (SEM) , Figure (1) shows theimages of CdS thin films before and after annealing process by $(\mathrm{SEM})$ in $(50 \mathrm{Mm})$.


Fig. (1):SEM images of Cds thin film before and after annealing in under different temperatures and in magnification (1000X)

\subsection{Histogram of CdS thin film images}

We used the program (Matlab2010) for studing the histogram images of thin films, which were images of gray (Gray scale images), which range between two values is $(0)$ which represents the color black and (255), which represents white. We note from the charts that increasing the temperature of annealing leads to a tendency the scheme peak towards the value (255), color white, and we can deduce from this that the increase in temperature annealing reduces the number of pores and their distribution on the surface of the Thin Film, This corresponds with the results that we obtained from the application program on the resulting images. The histogram of image shown in fig.(2).

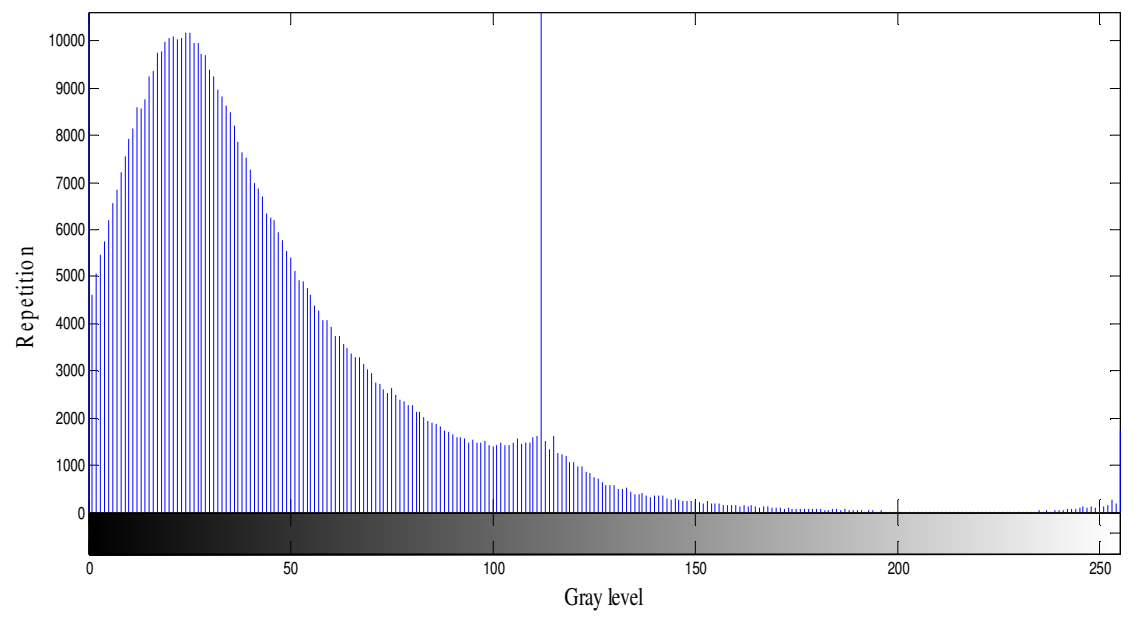

a. Before the annealing $\left(200 \mathrm{C}^{\circ}\right)$ 
International Journal on Soft Computing (IJSC) Vol.3, No.3, August 2012

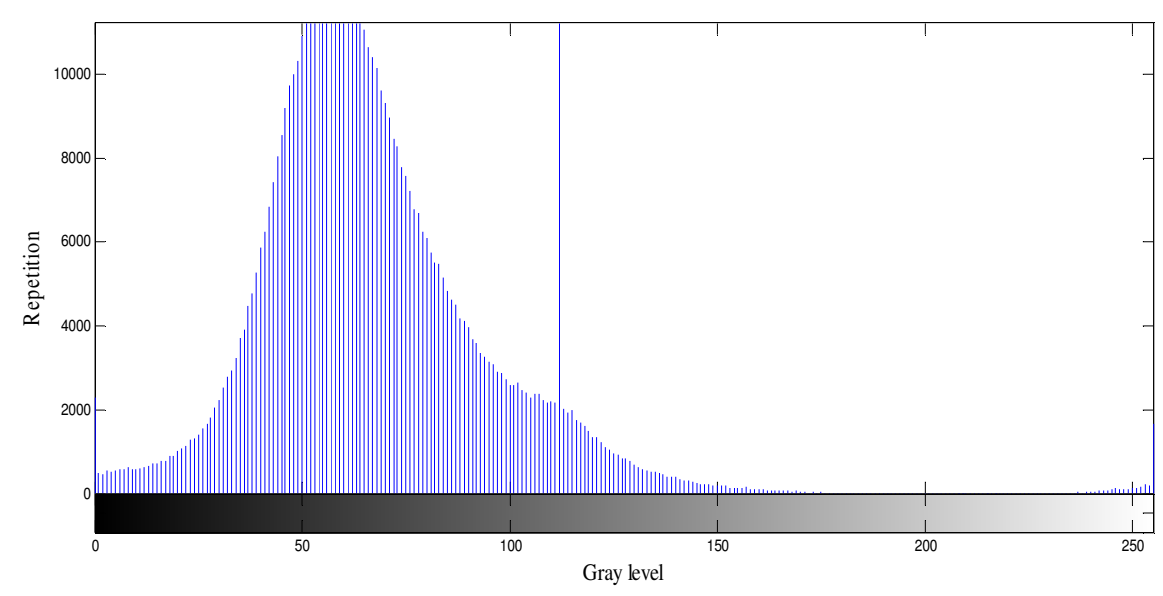

$250 C^{\circ}$

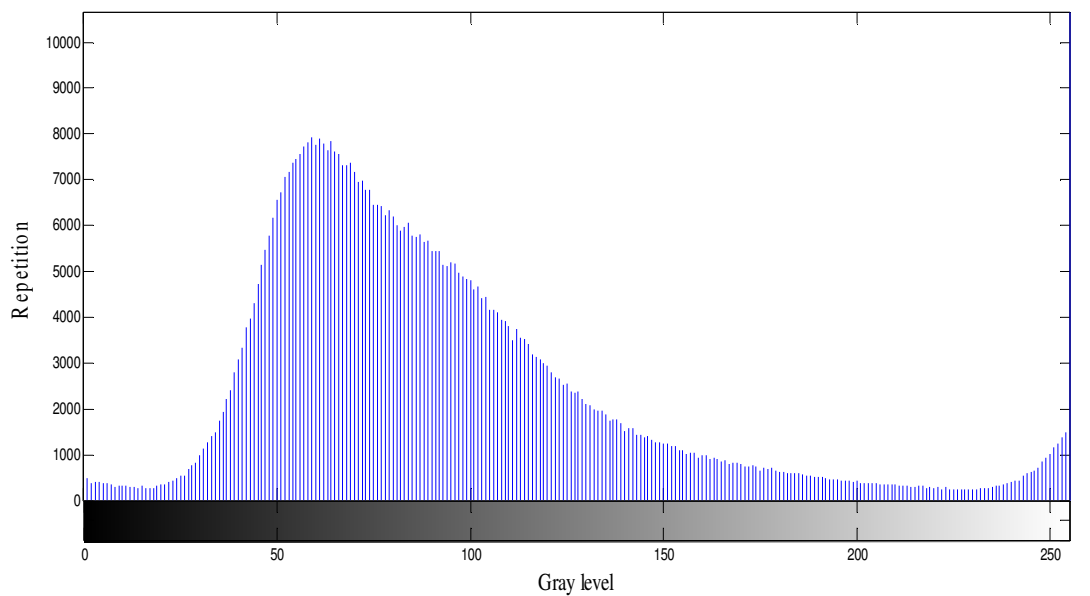

$300 \mathrm{C}^{\circ}$

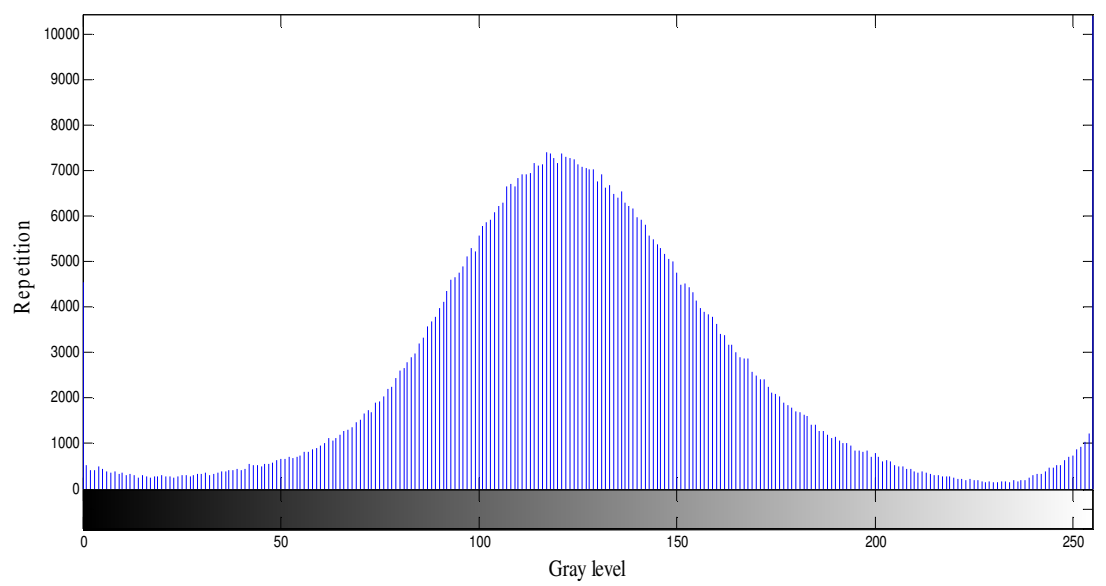




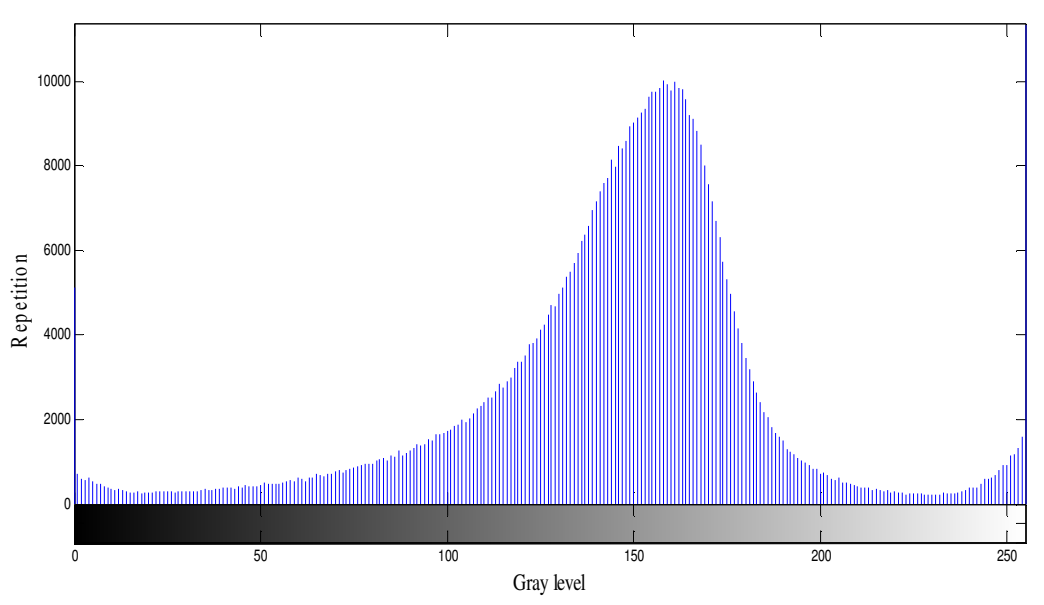

$400 \mathrm{C}^{\circ}$

Fig.(2) :The histogram of the distribution of the grey level of the Cdsthin film digital images before and after after annealing in under different temperatures.

\subsection{Binarization by Multithresholding}

AfterCdS thin films Images acquisition by (SEM), conversion of the gray scale images to binary images. There are two methods to calculate threshold (histogram and traditional method ). First, Histogram shows the number of pixels for each gray value within the range of the image gray scale. If the minimum value of the image is 0 and the maximum value of the image is 255 , then the histogram of the image shows the number of pixels for each gray value ranging between 0 and 255. Peaks in the histogram represent more common gray values within the image that usually consists of nearly uniform regions. Valleys in the histogram represent less common values. Empty regions within the histogram indicate that no pixels within the image contain gray values belong to these empty regions. Then the conversion from gray image to binary image could be done by using thresholdingmethod
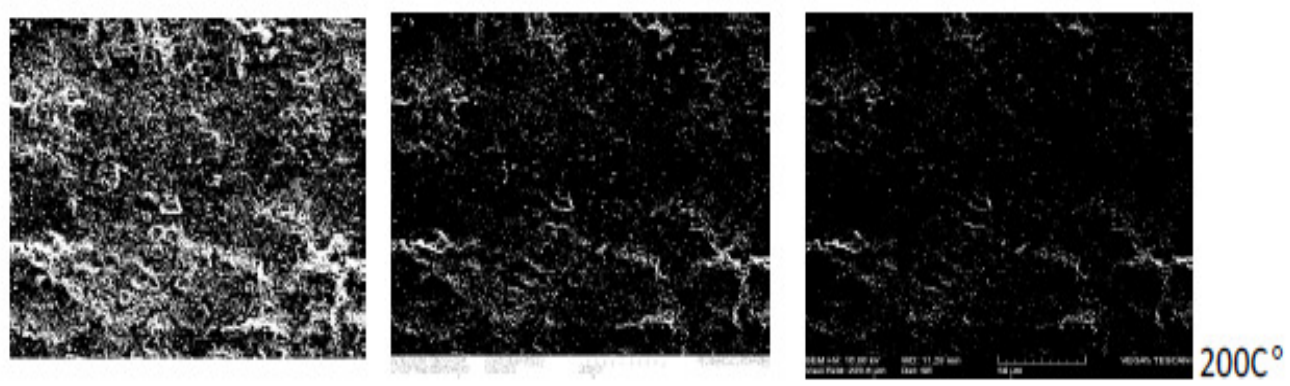

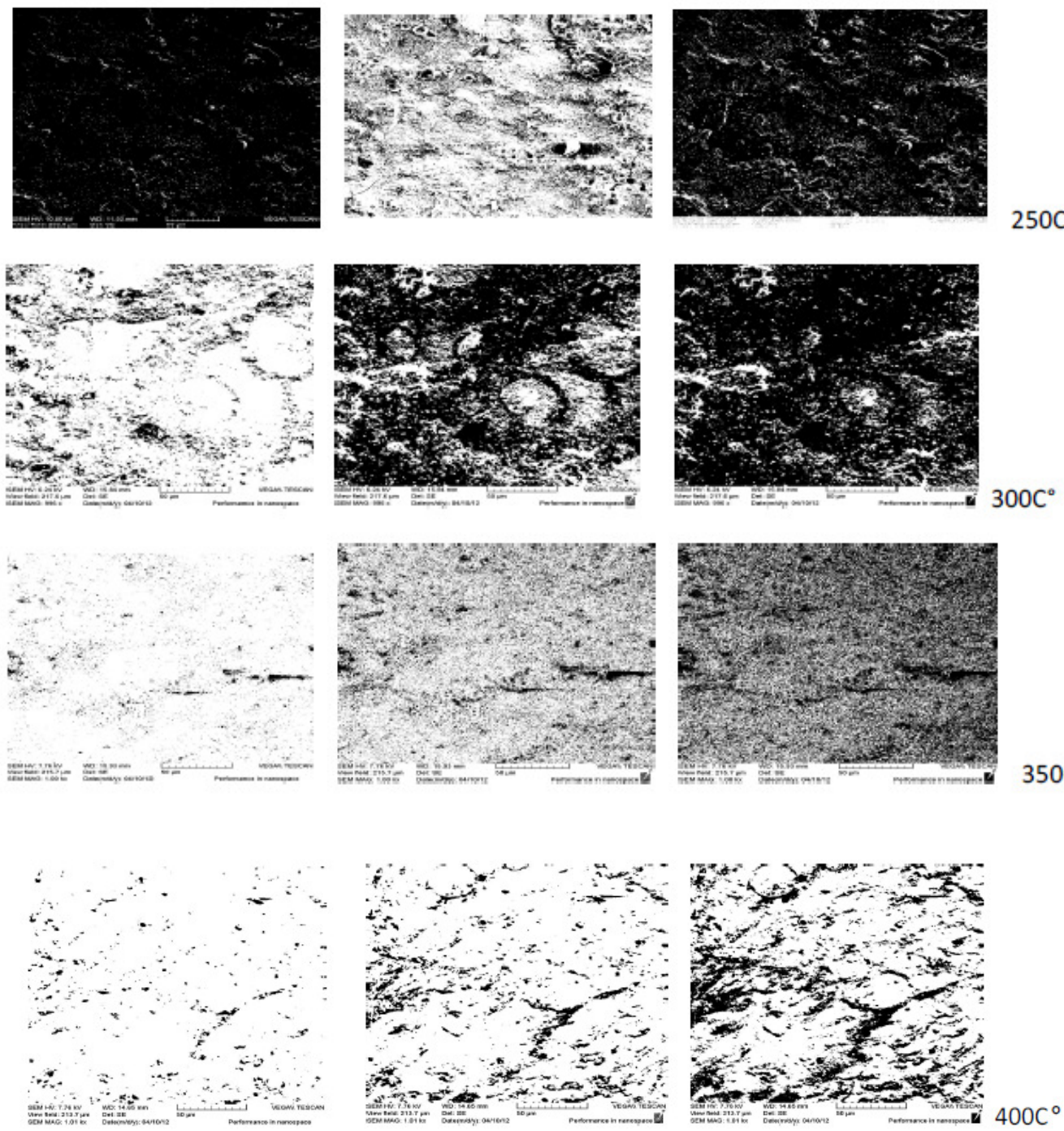

Threshold $=50$

Threshold $=100$

Threshold $=128$

Fig(3) :Binary images of CdS thin films $\left(200,250,300,350\right.$ and $400 \mathrm{C}^{\circ}$ respectively)in magnification $(1000 \mathrm{X})$

\subsection{Determination of porosity by using image processing}

We applied Seed Filling Algorithm on images of (CdS ) thin films by a scanning electron microscope (SEM) after conversion of Gray Scale Images to binary images in multithreshold to find a rate and the numbers of the pores on the surfaces of these thin films and study the effect of annealing under different temperature on the distribution of these thin films pores and percentage of thetotal area of the thin films, the flow chart of the seed filling algorithm is shown in figure (3). 
International Journal on Soft Computing (IJSC) Vol.3, No.3, August 2012

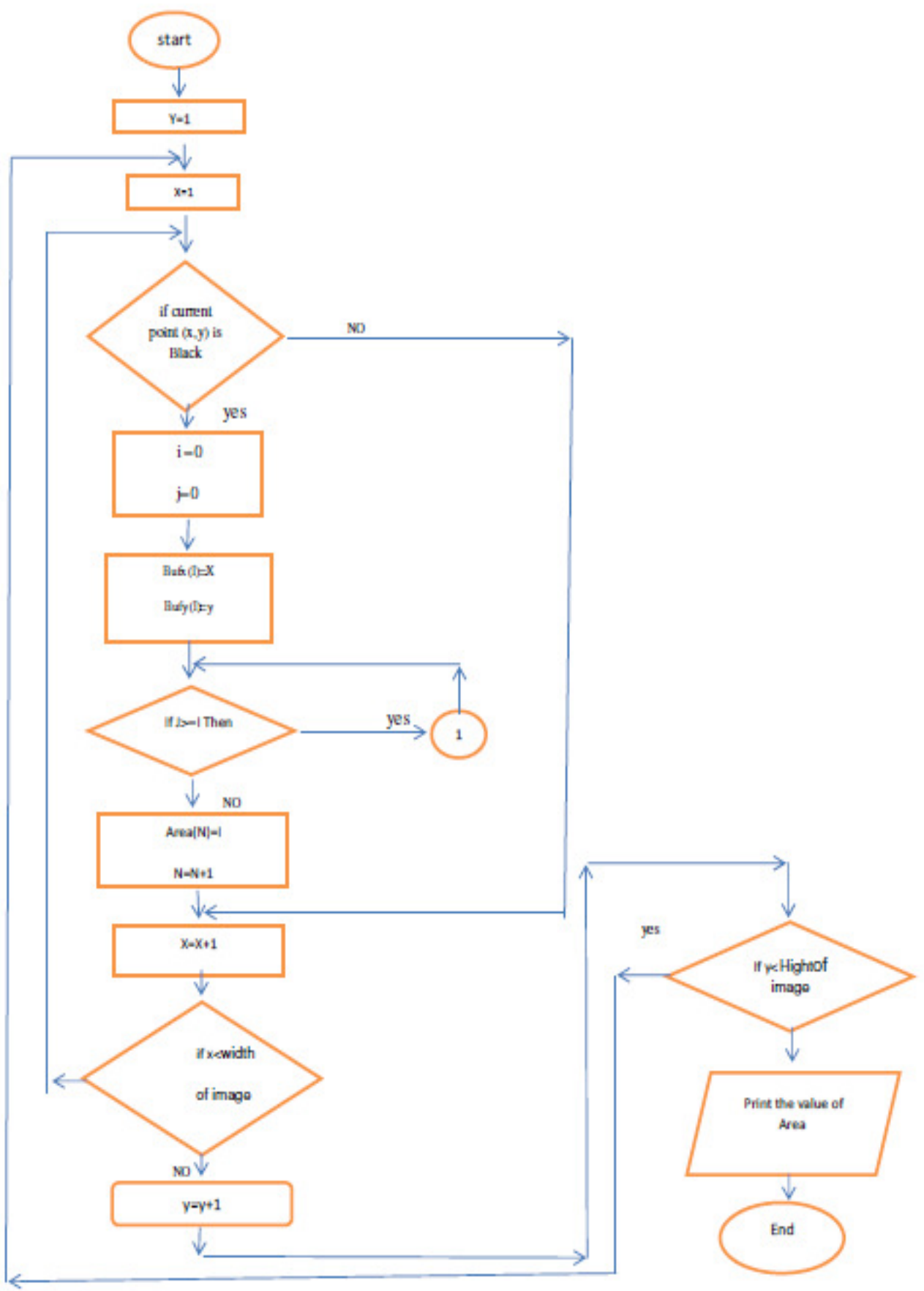


Where

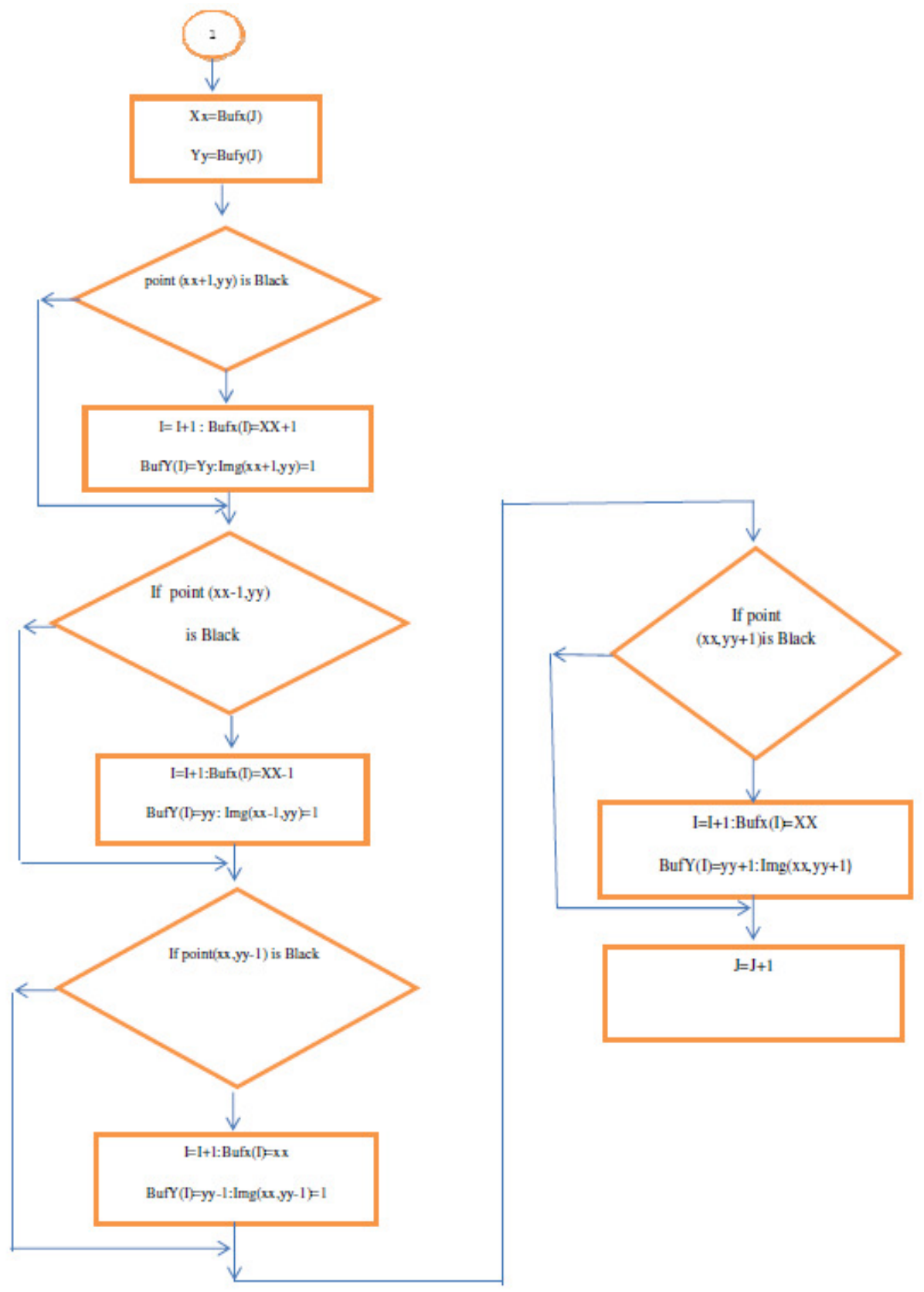

Fig.(3): The flow chart of seed filling algorithm 


\section{4- EXPERIMENTAL RESULTS}

Through our use of the algorithm we were able to calculate the porosity of each sample of the samples the membranes used and the effect of temperature annealing the ratio porosity on the surfaces of thin films of surface area overall, and the following tables show numbers and percentages pores on the surfaces of thin films before $\left(200 \mathrm{C}^{\circ}\right)$ and after annealing $\left(250,300,350,400 \mathrm{C}^{\circ}\right)$ and for selected and different threshold.

Table (1): numbers and percentages pores on the surfaces of thin films if threshold(128)

\begin{tabular}{|c|c|c|c|}
\hline \multicolumn{4}{|c|}{ Threshold $=128$} \\
\hline Temp. $\left(\mathbf{C}^{\circ}\right)$ & Number of regions & Total area & $\begin{array}{c}\text { Black } \\
\text { ratio(\%) }\end{array}$ \\
\hline 200 & 3 & 240896 & 91 \\
\hline 250 & 1 & 242447 & 92 \\
\hline 300 & 88 & 204484 & 78 \\
\hline 350 & 2256 & 142666 & 54 \\
\hline 400 & 916 & 61461 & 23 \\
\hline
\end{tabular}

Table (2): numbers and percentages pores on the surfaces of thin films if threshold(100)

\begin{tabular}{|c|c|c|c|}
\hline \multicolumn{4}{|c|}{ Threshold $=100$} \\
\hline Temp. $\left(\mathbf{C}^{\circ}\right)$ & Number of regions & Total area & $\begin{array}{c}\text { Black } \\
\text { ratio }(\%)\end{array}$ \\
\hline 200 & 18 & 231688 & 88 \\
\hline 250 & 35 & 225923 & 86 \\
\hline 300 & 476 & 168771 & 64 \\
\hline 350 & 3958 & 41508 & 15 \\
\hline 400 & 794 & 27430 & 1 \\
\hline
\end{tabular}


International Journal on Soft Computing (IJSC) Vol.3, No.3, August 2012

Table (3): numbers and percentages pores on the surfaces of thin films if threshold(128)

\begin{tabular}{|c|c|c|c|}
\hline \multicolumn{4}{|c|}{ Threshold $=50$} \\
\hline Temp. $\left(\mathbf{C}^{\circ}\right)$ & Number of regions & Total area & $\begin{array}{c}\text { Black } \\
\text { ratio(\%) }\end{array}$ \\
\hline 200 & 355 & 180352 & 68 \\
\hline 250 & 2885 & 64465 & 24 \\
\hline 300 & 1530 & 34343 & 13 \\
\hline 350 & 378 & 4171 & 1 \\
\hline 400 & 370 & 7461 & 2 \\
\hline
\end{tabular}

\section{CONCLUSION}

From the results we have obtained in our research that conclude that the proportion of porosity on the surface of $\mathrm{CdS}$ thin film less in higher annealing temperature, because the annealing works on recrystallized grains of the thin film so the white areas are growing and which represents the surface of thin film and the other hand, the black areas less than which represent pores ,cracks and defects on the surface of the thin membrane.

\section{REFERENCE}

[1] Nimmo . J. R., Porosity and pore size distribution, in Hillel, D., ed. Encyclopedia of Soils in the Environment: London, Elsevier 3, pp (295-303), (2004).

[2] Xavier M. and Jose S. Cruz, CdS thin film post-annealing and Te-S inter diffusionin a $\mathrm{CdTe} / \mathrm{CdS}$ solar cell, Solar Energy (2011). www.elsevier.com/locate/solener

[3] Jordan Peckham and G. Todd Andrews, Simple optical method to determine the porosity of porous silicon films, Thin Solid Films 520 , pp (2526-2531), (2012).

[4] Isabelle Masselin and Laurence Durand-Bourlier, Membrane characterization using microscopic image analysis, Journal of Membrane Science 186, pp( 85-96), (2001).

[5] Chun Liu and Bin Shi, Quantification and characterization of microporosity by image processing, geometric measurement and statistical methods :Application on SEM images of clay materials , Applied Clay Science 54, PP( 97-106), (2011).

[6] MALIK .S. Hayat," Modified new Algorithm for seed filling", " Journal of Theoretical and Applied Information 26, pp(28-32),(2011).

[7] Deshpande .S., Application of image analysis for characterization of porosity in thermal spray coatings and correlation with small angle neutron scattering, Surface and Coatings Technology 187, $\mathrm{pp}(6-16),(2004)$.

[8] Weina Sun , A study on membrane morphology by digital image processing, Journal of Membrane Science 305, pp (93-102), (2007).

[9] Stephen.H. Stoker, " Introduction to Chemical Principle " (1983). 


\section{Author}

${ }^{1}$ Azmi TawfikHussain was born in Anbar - 1961. He got on B.S c of physical in salhdee university 1983 - Iraq and M.Sc. in theoretical physics in al yarmook university 1992 - Jordan and Ph.D. in Image Processing from in al-mustinsary university - Iraq, (2001). He interesting in the follow filed (fractal geometry, image recognition, theoretical physics, signal processing). He publish many paper in different conferences and scientific and scientific journals

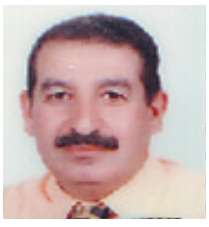

${ }^{2}$ Saad Jasim Mohammed was born in Anbar - 1988. has received B.Sc iof physical in Al-Anbar University, Iraq, (2006-2010) and M.Sc in Physics Department, Al-anbar University, (2012). Fields of interest: theoretical physics, image processing, and related fields.

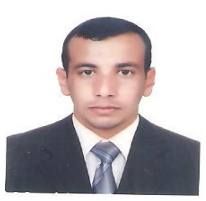

